Article

\title{
A Migration Project in Retrospect: The Case of the Ageing Zero Generation in Emirdăg
}

\author{
Christiane Timmerman *, Meia Walravens, Joris Michielsen, Nevriye Acar and Lore Van Praag \\ Centre for Migration and Intercultural Studies, University of Antwerp, 2000 Antwerp, Belgium; \\ E-Mails: christiane.timmerman@uantwerpen.be (C.T.), meia.walravens@uantwerpen.be (M.W.), joris.michielsen@klina.be \\ (J.M.), kan_kirmizi_58@hotmail.com (N.A.), lore.vanpraag@uantwerpen.be (L.V.P.)
}

* Corresponding author

Submitted: 30 March 2018 | Accepted: 12 June 2018 | Published: 30 August 2018

\begin{abstract}
In the twentieth century, Emirdağ (Turkey) witnessed extensive emigration and is now home to the 'zero generation': a group of elderly people who stayed behind when their children moved abroad. We investigate how these elderly people, with at least one child who left the country, evaluate their situation as they have grown older. Using fieldwork observations and in-depth interviews, we found that this group mainly associated the migration of their offspring with loneliness and exclusion from society, due to separation from their children and changes in the traditional family culture. The respondents clearly note a shift in the social position of family elders in Turkish culture, from highly respected to being ignored and looked down upon. While this change in status might be experienced by all elderly inhabitants of the region, feelings of distress were reinforced by an emerging discourse which suggests the migration project is a failed enterprise. The constraints their children experience in the immigrant country have led the zero generation to rely less on them and become more dependent on their own resources. Future research on ageing, migration and transnational care should focus on the different ways in which migration systems evolve, and the long-term effects on social inclusion of all generations.
\end{abstract}

\section{Keywords}

ageing; elderly; migration; Turkey; zero generation

\section{Issue}

This article is part of the issue on "Migration, Boundaries and Differentiated Citizenship", edited by Terry Wotherspoon (University of Saskatchewan, Canada).

(C) 2018 by the authors; licensee Cogitatio (Lisbon, Portugal). This article is licensed under a Creative Commons Attribution 4.0 International License (CC BY).

\section{Introduction}

In the twentieth century, Emirdağ, Turkey, experienced extensive emigration (De Haas, 2001; İçduygu \& Sert, 2016; Timmerman, Lodewyckx, \& Wets, 2009). This led to the creation of a culture of migration, reflecting the overall popularity of emigration within the region (De Haas, 2001; Timmerman, Hemmerechts, \& De Clerck, 2014), as well as a change in the ways these now transnational families function and take care of each other (Baldassar \& Merla, 2014). The issue of caring is becoming increasingly important, as these emigration patterns also led to the creation of the 'zero generation', a term that has been employed by various scholars in migration research to refer to a group of parents who did not migrate but became part of transnational families when their children moved abroad (e.g., King, Cela, Fokkema, \& Vullnetari, 2014; Nedelcu, 2009). The migration trajectories of this zero generation may also be quite variable, as some in this group have followed their children and migrated as well, while others have engaged in transnational mobility, moving back and forth between the two countries (King et al., 2014). As they grow older, members of the zero generation need increasing care, which puts existing care systems under pressure and changes the nature and reciprocity of care (Baldassar \& Merla, 2014). Previ- 
ous studies introduced the concept of the zero generation as a new unit of analysis to efficiently examine and describe their subject of study. They demonstrated the importance of also including non-migrant parents in migration studies (King et al., 2014; Nedelcu, 2009). Despite these initial explorative studies and the development of important migration systems between Turkey and Western Europe since the 1960s (İçduygu \& Sert, 2016), little research has focused on the Turkish zero generation.

The consequences of migration for the distinct life spheres of this zero generation need to be examined in greater depth to fully assess the needs of the elderly living in Turkey who are part of transnational families. Research on the contribution of migration to the health status of this zero generation in transnational families is inconclusive. On the one hand, direct beneficial effects of an adult child's migration on the physical health of elderly parents have been reported, such as better Body Mass Index (BMI), increased mobility, better self-reported health (for Moldova, see Böhme, Persian, \& Stöhr, 2015), and a reduction in mortality risk (for Indonesia, see Kuhn, Everett, \& Silvey, 2011). On the other hand, there are also negative impacts of a child's emigration on the mental health of elderly parents, such as increased symptoms of depression, loneliness and sadness and even deteriorating physical health (for Mexico, see Antman, 2013).

To better understand these different effects of migration on the health of the elderly zero generation, more attention should be paid to the care arrangements in both the sending and receiving countries. More specifically, by looking at the contribution of migration to care for the elderly zero generation, the concept of the 'circulation of care' is revealing. This concept was defined by Baldassar and Merla (2014) as the:

reciprocal, multidirectional and asymmetrical exchange of care that fluctuates over the life course within transnational family networks subject to the political, economic, cultural and social contexts of both sending and receiving countries. (Baldassar \& Merla, 2014, p. 25)

The introduction of this concept is relevant as it allows us to document the unforeseen and unintended consequences migration circuits may have for both migrants and (relatives in their) communities of origin. Thus, when looking at the circulation of care for the zero generation, more research is needed to examine how this varies across specific migration contexts, and how it impacts the prevailing culture of migration, and what type of support is given by children to their parents, and vice versa. For example, in Romania, Zimmer, Codrina and Stoica (2014) found that, in line with common expectations, children who live further away from their parents tend to provide them with more financial assistance for their care, in contrast to those living nearby, who take upon themselves the direct, instrumental care, for which they need to be physically present. Similarly, in Cambo- dia, Zimmer and Knodel (2013) observed the same mechanism and concluded that the migration of a child usually indicates a positive evolution for a parent, as the monetary support they receive increases, while they do not lose out on other types of support.

We aim to contribute to the literature on the zero generation, transnational care and ageing in the context of migration by focusing on a long-established migration system, which could be said to have seen a decline in recent years. We will demonstrate that even in migration systems with a long history, the establishment of transnational familial bonds that ensure the provision of the necessary care is not an obvious outcome. The results of the research contribute further knowledge on the development of a culture of migration and whether it can be interpreted as a failed or successful enterprise, influencing further chain migration (De Haas, 2001; De Haas, Fokkema, \& Fihri, 2015; Timmerman et al., 2009, 2014). First, we will specifically examine the impact on one particular life sphere, namely elderly care, and determine how issues concerning this care also relate to migration issues and discourses. Second, by examining the transnational family care arrangements, or the lack thereof, we will gain greater insight into the actual support parents receive from their migrant children, as well as the reciprocal nature of this support. As such, we move away from the general depiction of transnational care as limited to the impact of an adult child's migration on the financial well-being and health of the zero generation, and recognise that the zero generation is actively involved in negotiating the consequences of their adult children's migration and cannot be merely conceived as passive bystanders (Baldassar \& Merla, 2014). We will do so by focusing on Emirdağ, a region in Turkey that has witnessed considerable emigration to Western Europe. In the following sections, we will set out the migration context of this region in greater depth, describe how it gave rise to a particular culture of migration (Timmerman et al., 2009, 2014) and how transnational care is organised.

\section{Research Context}

\subsection{The Migration Context in Emirdağ}

Emirdağ is a district in the province of Afyon. The primary town in the district bears the same name and is the scene of our research, together with some smaller villages in its direct vicinity. When comparing all districts in Turkey in terms of socioeconomic situation, development and urbanization, Emirdağ generally falls just below average in rankings (Karcl, Üstübici, \& De Clerck, 2010). The region of Emirdağ is situated on the central Anatolian plateau around 1000 metres above sea level with a semi-arid climate. Agriculture in the region is difficult and industry is relatively underdeveloped, while the service sector, although also limited, is the healthiest economic sector (Karcl et al., 2010; Teule, Vanderwaeren, MbahFongkimeh, \& Timmerman, 2012). 
The signing of a bilateral agreement between Belgium and Turkey in 1964 sparked the first emigration waves from Emirdağ to Belgium, which has remained the primary destination, although the Netherlands, France, Switzerland, Germany, Sweden and Denmark have also received tens of thousands of immigrants from the region. In 1974, Belgium stopped accepting Turkish migrants for labour, but migration continued through family reunification and the arrangement of tourist visas, often resulting in the creation of 'transplanted communities', with most members of such communities coming from the same region (Timmerman, 2006, 2008; Van Kerckem, Van de Putte, \& Stevens, 2013). Consequently, marriage now remains one of the few means to migrate and enter Europe legally, although overall emigration numbers are decreasing (Timmerman et al., 2009).

This long history of migration, creating a 'tradition' of emigrating to Europe, and the positive image of Europe which was promoted by migrants who returned home temporarily, has created a culture of migration in Emirdağ (Timmerman et al., 2014). Despite the initial positive image of Europe, however, the perceptions about economic opportunities and living conditions in Europe have changed in Emirdağ, with more negative migration aspirations now becoming apparent. This is due to the recruitment of the labour force for manual labour, the low degree or lack of formal education of most migrants, and the difficult working conditions faced by migrants coming from this region. Consequently, migration aspirations in Emirdağ have become even lower than those in a similar city in the same region that has not been affected by migration to the same extent (Timmerman et al., 2014).

Not only have perceptions about migration changed, but also related practices. Before Europe experienced a period of recession, the population of Emirdağ used to triple in the summer as many migrants returned temporarily to visit family and friends. However, due to the recession and the weakening of the third generation's ties with Emirdağ, the number of returnees in summer is decreasing. Some also prefer to spend their holidays on the Mediterranean coast rather than in Emirdağ (KarCl et al., 2010). Similarly, there has also been a general decrease in remittances sent back to Turkey. According to the Balance of Payment Statistics of the Central Bank of the Republic of Turkey, remittances started to decline significantly after 1998. In this year, 2.8 million Turkish expats sent USD 8.2 billion back to Turkey. Although the number of migrants further increased to 4.3 million in 2012, remittances dropped to USD 961 million (World Bank, 2015). This decline in the extent of remittances in Turkey should also be seen in conjunction with other developments in Turkey, such as the increase in expenses in other domains, such as in tourism and exports (Içduygu, 2005).

This decrease in remittances might also reflect the changing migration dynamics, which can be related to a number of factors, including: permanent residency in the host country; higher living costs and weaker attach- ment to the homeland; changes in the socioeconomic status of the immigrants and their descendants; a second and third generation that prefer to invest in their own businesses in the host country rather than their family back in Turkey; the political environment; the economic policies in the host and home countries; dropping interest rates; and a rise in tax on remittances (Bettin, Elitok, \& Straubhaar, 2012; Içduygu, 2005; Koc \& Onan, 2006). Finally, changes in the family situation of the migrant and non-migrant households may influence or stop remittance flows. For example, unmarried migrants without children of their own tend to send more money than those who are married or who have children. Remittances from migrant daughters can also change when they marry, as they generally channel their care and remittances to their husbands' parents (Coles, 2001; King et al., 2014). As to familial changes on the receiving side, the death of a father may end remittances to the mother if this weakens the son's filial piety, or remittances may be redirected to another male household member (Coles, 2001). All these developments concerning emigration from Turkey have an impact on the zero generation in Emirdağ, as we will demonstrate below.

\subsection{Transnational Care in Turkey}

The role of the family in providing care to elderly family members is believed to remain important despite migration, and this is a question of utmost importance to the zero generation. In relation to Turkey, only a few studies (Coles, 2001; Şenyürekli \& Detzner, 2008; Bilecen, 2013) have examined the provision of care or the arrangements within families with members that have migrated in the recent past. Bilecen (2013) illustrated how protective resources flow between Germany and Turkey, distinguishing between informational exchange, care relations, financial protection and social activities such as having meals, doing sport and having tea. Coles (2001) found that the traditional social hierarchy in rural families changes, specifically concerning care relations, and her study showed how this often leads to feelings that care for the elderly is often not sufficiently valued. Furthermore, in their study of intergenerational relationships between Turkish families in the US and Turkey, Şenyürekli and Detzner (2008) mention the stress felt by the US-based migrants, due to the necessary flexibility required in terms of time, holidays, transportation and financial resources, should they need to travel to Turkey in an emergency. This stress is also seen as one of the drivers of Turkish migrants returning from the US to Turkey or settling in Europe (Şenyürekli \& Menjivar, 2012).

If one considers that family and children are the two most important factors that contribute to the happiness of the elderly in Turkey (TurkStat, 2015), it is logical that separation from one's migrant family can lead to feelings of loneliness and eventually to unhappiness and mental disorders (Coles, 2001). Furthermore, changes in future 
prospects contribute to poorer mental health of the rural elderly in Turkey. First, being alone late in life is not what they expected in terms of intergenerational relationships and filial responsibilities. Many members of the zero generation grew up in extended households following a patrilocal pattern of residence (for Albania, see King et al., 2014). Second, more so than the reduced social support from migrating daughters, the loss of filial responsibility usually reserved for the adult male children and the change in the power hierarchy between the parents and daughters-in-law who have migrated seems to result in a loss of social status and feelings of isolation, especially in rural female elderly. Parents often go to live with their son and daughter-in-law and must adjust to their household organization and rules (Coles, 2001; for Albanian elderly see also King et al., 2014). Third, tied with health concerns, rural elderly people have constant concerns about the future and the necessary health and aged care they require (Coles, 2001).

\section{Methodology}

Our research aims to provide insight into the effects of a child's migration on the elderly zero generation in Emirdağ, a specific generation created by the mass emigration to Europe between the 1970s and 1990s. We began with participant observations in Emirdağ, covering a period between 1990 to 2018, carried out by one of the authors. We also included field observations, interviews and surveys in the context of the EUMAGINE project in 2011 and a study of the zero generation in the summer of 2015. Over the years, one of the researchers spent some period of time in Emirdağ nearly every year, residing with local families, and following up on the dynamics within the culture of migration that emerged in the region from the 1970s on. This was described in her PhD research and other studies on the migration context in Emirdağ (e.g., Timmerman, 1995, 2006, 2008; Timmerman et al., 2009, 2014). Targeted information for this article was also collected through interviews in 2015 with several very elderly parents whose children left when emigration to Europe gained momentum. We also interviewed key informants who, because of their professional or social status, were well placed to give their perspective on the situation. In total, 14 elderly parents accepted our invitation to talk about their situation in the summer of 2015. We focused on interviewees who lived in the city of Emirdağ or a neighbouring village and had at least one child living abroad who had left for Europe at the height of the emigration era in Emirdağ. Our sample consisted of two people living in the centre of Emirdağ, nine in a neighbouring village and three in residential care. Ten of the respondents were women and four men, with an average age of 81.6 .

The zero generation respondents were selected and contacted with the help of key informants who were already acquainted with the issue and who could comment based on their own experience and position in so- ciety, such as local politicians, businessmen and social workers. Additionally, 14 of these key informants also participated in an interview, in which they were asked about their views on the position of elderly people in contemporary society and the effects of migration on their lives.

The interviews for the research were based on semistructured questionnaires addressing six central themes: 1) opinions of the respondent about the quality of life in Emirdağ; 2) opinions about the status of elderly people in family life and society in general; 3) opinions about migration: 4) the relationship with family members living abroad; 5) physical and mental health of the elderly respondents; and 6) wishes and needs of the elderly respondents. In the interviews with the key informants, we asked them about their views on the situation of the very elderly zero generation in Emirdağ.

All of the interviews took place in an environment which allowed the interviewees to feel as comfortable as possible, such as their own homes, the retirement home or another place of their choice. All of the interviews were recorded (after agreement), except for two interviews with key figures and one with an elderly woman. The interviewer spoke Turkish, the mother tongue of the interviewees. Afterwards, the interviewer translated the recordings and notes for analysis into Dutch and English.

A thematic approach was chosen to analyse the data. First, two researchers coded and analysed the translated interviews separately in order to ensure objectivity of the results. The researchers in this phase treated the interviews with the elderly zero generation and with the local key informants as two distinct sets and composed two thematic lists, one for each participant group. In a second stage, these thematic lists were compared and brought together in order to contextualise the information received from the zero generation.

\section{Results}

The houses used to be small and inhabited by a lot of people, but now the houses are big and there is no place in them for anybody. (Female key informant, 23, social worker in a retirement home)

\subsection{The Historical Making of the Zero Generation}

Firstly, the research confirmed that the elderly inhabitants of Emirdağ viewed their city as greatly affected by processes of migration throughout its recent history. The first phase was in the 1960s, according to many of the respondents, with the lack of job opportunities in Emirdağ triggering a first wave of emigration from the region. Financial difficulties and poverty as a result of the economic situation in the region were seen as the main reason for emigration from Emirdağ, and many people are said to have left because they had no other choice. These findings are in line with results from the ongoing participant observation study conducted over the years in the 
region of Emirdağ (e.g., Timmerman, 1995, 2006, 2008; Timmerman et al., 2009, 2014). Their original intentions were to find a job abroad and to return with their savings later. According to a male key informant, middle-aged, lawyer in Emirdağ:

The people left because they had no money, they were poor, and this led them to migrate to a foreign country. The first of them left in the 1960s, having in mind to save some money and then return. But they didn't. They started a family there, or moved their family there, and the children born there, stayed there because they were used to it. They have their social networks.

Two of the interviewees were themselves among these first economic migrants. However, in contrast to the general perception among the interviewees that these migrants for the most part never returned, these two people did find their way back to Emirdağ. One of them returned because he became ill as a consequence of the unhealthy working conditions, while the other left Europe to care for his ageing mother. A third respondent, 87, living in a retirement home in Emirdağ, described his own migration path within Turkey and stated that he returned because he missed his hometown: "I worked in other cities, like Bursa, for a long time. To be far away from home is also a kind of migration. I missed it too much".

In a second phase, between 1980 and 1990, migration was not only a way to escape poverty, but came to be seen as an opportunity to make good money quickly, and many young people left in search of wealth and riches (Timmerman et al., 2009). It is this migration wave in which many children of the respondents took part. "If they had stayed here, they would have become hard workers", says a female respondent, 70, currently living in a village of Emirdağ. She continues: "They already used to work hard and right when things began to sort themselves out, Europe became more interesting to many, including to my children".

As a consequence of the historical importance of migration in the narratives of all of the respondents, all of the elderly men and women interviewed could be rightly said to exemplify what has been described as the zero generation. Their life histories are invariably connected with the migration projects of their fellow community members, friends, family and direct offspring, and have shaped their views on migration and on life in general. Looking back on their own lives and the migration project of their children, the interviewees referred to a number of negative consequences of migration, which could broadly be summarised as: the consequences for the family left behind (i.e., for the elderly people themselves), the consequences for the children who migrated, and the consequences of migration in Emirdağ in general.

\subsection{The Migration Project of their Children in Retrospect: The Consequences for the Zero Generation}

The most regularly occurring consequence mentioned by the interviewees in relation to themselves was the inevitable feelings of loneliness in the long periods that their children were away, and that they must live on their own: "No, I have nothing to complain about", says a male respondent, 83, living on his own in the village of Karacalar to the southeast of Emirdağ. "The only thing that makes things hard is the constant feeling of loneliness". A female respondent, 89, living on her own in the centre of Emirdağ, elaborates:

It feels very bad to stay behind alone, I am sad. I find it difficult when my daughter-in-law returns home in the evening, while she spends the whole day here. You are old and you are afraid of dying alone. I cannot take care of myself anymore. If I fell, I would not be able to get up anymore. Loneliness is very bad.

Some respondents in this context even referred to extreme examples of their situation. One of them described how he sits the whole day looking at the door, waiting for someone to pay him a visit. Another woman spends the whole day next to the phone, waiting for one of the sporadic phone calls from her children, which would leave her beaming with joy. Others recalled how some elderly people they knew had died alone and were found in their homes only days later. A male respondent, 86 , living on his own in the village of Suvermez to the east of Emirdağ, said:

We married off one of our daughters to a boy from there [Europe]. Our son did not like it here, so he married someone from there as well and left. They do not get along well, however. My son works there now. It was difficult to let them go. My daughter divorced her husband because they did not get along well either. I lost my wife in 2009, she suffered from a brain tumour. I asked my neighbours to call me from time to time, so they may find me when I am dead.

Regardless of the number of children or their place of residence, it was mainly the overall feeling of being left alone and not having someone nearby to help them with their daily needs and care that was most often mentioned by the respondents. According to our findings, the situation of this zero generation was aggravated by their perception that not only their children had deserted them, but also that they had nobody at all to take care of them. "I have heart problems", explains a female respondent, 90, living on her own in the village of Güneysaray to the west of Emirdağ:

They took me by ambulance to Afyon. My son could not make it, so I went there on my own. In one month, 
I had to go to Afyon four times. I am ill, but still I do everything myself. Nobody comes knocking on your door asking how things are. I sit here on the balcony for the whole day, staring outside. I pay someone to do the tasks I cannot do myself anymore.

Connected to this are feelings of sadness, longing and disappointment. Most elderly people are disappointed about the outcome of the investments they made on behalf of their children. They do not think their children are grateful. "I did everything for my children, but now I see how it has all been for nothing" says another female respondent, 82, living on her own in the village of Karacalar to the southeast of Emirdağ: "I sit here all by myself. And I am not the only one, a lot of people are dissatisfied with their children".

A second change that the respondents noted as a consequence of the migration of their children was in their financial situation. They observed that remittances from their children strongly declined around 1998 (see Içduygu, 2005; TurkStat, 2015). A significant number of the parents had once received money from their children, but now their children had too many financial difficulties themselves (see also Bettin et al., 2012). Others said that, in general, they did not receive anything anymore from their children, because they are entitled to a state pension. Our results are in line with the findings of Koc and Onan (2006), who found that elderly people in the country of origin do not receive financial help from their family abroad. "They [the children] say they have financial difficulties themselves and therefore they do not send me anything. They have never sent me money" says a female respondent, 75, from her home in the centre of Emirdağ. "They [the children] say that the retirement pension I get suffices", says another male respondent, 86, living on his own in the village of Suvermez: "They have their own obligations and a family for which they are responsible, so I do not expect anything from them".

Initially, both migration and remittances are seen as risk-spreading and co-insurance livelihood strategies by households and families (De Haas, 2007; De Haas et al., 2015). However, especially according to the elderly in our sample-who supported their children in their migration project, not only to secure them a better living, but also to ensure that they would have sufficient resources to be taken care of as they aged-their efforts have not paid off. From this migration perspective, less support was expected from other public or communitybased support systems. Apart from the decline in remittances, the respondents indicated that their financial situation had deteriorated because when their children left they were left on their own financially. All of the elderly respondents belonged to the lower social class and most of them were not entitled to receive a retirement pay out. The women, in particular, had a hard time securing sufficient financial means to survive. Some of them received a small amount of financial support from the state after their husbands had passed away, but this was only the case for legally married women, and not for those who married their husbands as a second wife under religious law (see also Basara, Mollahaliloglu, Pulgat, \& Kavuncubasi, 2014). The elderly respondents who did not receive a pension said they survived on gifts, religious financial help, and earnings from small jobs. A female respondent, 82, living on her own in the village of Karacalar to the southeast of Emirdağ, notes:

Every two months I receive 500 lira [approximately EUR 156 or USD 177 at the time of writing] because I am a widow. I try to manage. It is not enough, but I try to manage anyway. I pay the electricity and water bills with it.

We can conclude that the feelings of loneliness and disappointment are related to the lack of overall care that these elderly people receive and the inability-in terms of financial means - to find care elsewhere as an alternative to the lack of familial emotional, practical and financial support. Adding to the feelings of disappointment is the feeling that the migration of their offspring to Europe was a failure rather than a success. However, this does not apply to offspring who went to live in Turkey's big cities, because they are considered to be still 'at home' and taking part in the success story of the economic revival occurring at the time of the interviews.

\subsection{Consequences of Migration on Emirdağ}

The results of the research reveal that in the opinion of these elderly zero generation interviewees whose children left at a time when emigration from Emirdağ was at its height, migration did not bring their children economic relief. In contrast, most respondents noted how very hard it is to survive financially in Europe. In their opinion, this also negatively affected family ties, as they lacked the means to travel and visit one another. In addition, some respondents even said that the quality of life in Europe is worse than in Turkey. From a male respondent, 86, who lives on his own in the village of Suvermez to the east of Emirdağ:

Those who now return [to Turkey] for a holiday, including my son, say that Europe is over. There is a crisis going on and money flows away quickly. It is impossible to save anything, you should not imagine anything like that. My son says from time to time that he regrets having left [Turkey].

A logical consequence related to the phenomenon of the zero generation is the demographic ageing of the population of Emirdağ. According to some respondents, a decrease in production due to the ageing of the population resulted in an increase in living costs, which are much higher than in other small Turkish towns. Moreover, the surrounding villages also appear to have become less populated than before, due to the migration of 
the young people to larger Turkish cities and to Europe, as was also demonstrated in previous research (İçduygu \& Sert, 2016). Several of the key informants stated that in a few years, when the older generation has passed away, these villages will be completely empty and disappear. In some villages this is already the reality, with several deserted over the last decades (İçduygu \& Sert, 2016).

In addition to demographic and economic changes, the respondents observed a general change in moral values. According to some respondents, their family in Europe had lost their cultural identity, their religion and, most importantly, their sense of the importance of family values and connections. One example of this was their view on marriage. While migration to Europe through marriage to a European citizen was favourably judged in the past, the key informants now generally considered it as disruptive of traditional family life, arguably because many of these marriages ended in divorce (see also Timmerman et al., 2014).

Our findings indicate that all the respondents shared a similar view in the final evaluation of the migration project of their children: it has failed. For them, the negative consequences, such as loneliness, financial difficulties both in Europe and Turkey, and a change in family values, were more than enough to condemn migration as a useless aspiration. Some local informants even proposed that the Turkish state should organise the return of all those who had once left:

I think that the state should promote their return by facilitating a couple of things for the people who want to start a business here. It would also create more jobs for the people from here and they would not be tempted to leave anymore.

The respondents indicated that their evaluation of migration was shared by the whole community and that the negative connotation which migration had now acquired, had brought about a visible change in migration processes. For example, they observed that fewer marriages occurred in the summer months, which is generally the time when migrants return to marry their European fiancés. Also, they see more young people consciously deciding to leave for the larger cities of Turkey rather than Europe.

The most important change, however, was the visible emergence of the phenomenon of return migration. Generally, people now find that the situation in Europe has deteriorated, with the financial crisis also increasing discrimination, and that conditions in Turkey have improved. A key informant states:

Turkey is doing economically much better nowadays, and people stay here. There is also an evolution in social security: people get extra grants for their children, grants to start a business....This surely convinces people to start a business here.
Nevertheless, those who are returning are said to be wealthy and old, while the younger people who return more often move to the larger cities in Turkey rather than back to Emirdağ. "The reason why they return to cities other than Emirdağ is to avoid people talking about their failures, about the fact that they did not succeed", says a key informant: "That is what I, from my experience, think is happening".

Only one respondent said that he knew someone who, after returning to Turkey, moved back to Europe again, because his family could not get used to the country.

\section{Conclusion}

The present study built on the framework of care circulation (Baldassar \& Merla, 2014) and the culture of migration (De Haas, 2001; Timmerman et al., 2009, 2014), with the aim of understanding how ageing and transnational care is perceived by the zero generation in Emirdağ, a region that witnessed massive emigration over the last five decades, mainly by low skilled people who emigrated in the context of family reunification (Timmerman et al., 2014). Our study found that the now very elderly zero generation created between the 1970s and 1990s in Emirdağ, feel rather isolated from society, are disappointed by the lack of return for their investment in their children's migration project, and now find themselves in a particularly vulnerable life stage in which they need additional care. The respondents often referred to a shift in the social position of family elders in Turkish culture, from being highly respected to now being ignored and looked down upon. While this change in status might be experienced by all of the elderly inhabitants of the region, the isolation of this very elderly zero generation in particular is exacerbated by the absence of their children due to emigration. The reciprocity of care over their life span is perceived to be unbalanced and not worth the investment, leading them to believe that migration is a failed enterprise.

The latter reflects a changing culture of migration (De Haas, 2001; Timmerman et al., 2014). In the 1990s, there was a positive culture of migration, and emigration was considered a good investment in the future, resulting in chain migration to Europe (Timmerman, 2008). However, today, emigration has a negative connotation, which is reflected in a decrease in numbers of emigrants to Europe from Emirdağ (Timmerman et al., 2014). Moreover, the elderly generation feels that it has lost its sons and daughters, who are now unable to return because of financial constraints. The financial hardships of their children deprive the elderly zero generation of any monetary support, making them dependent on small state pensions, gifts and sometimes money received from selling part of their land or property.

The lack of compensatory care for these elderly people-due to financial constraints-further highlights the lack of support from their children. This case study 
shows that there are very important structural factors involved, related to institutional and familial care arrangements, the financially precarious situation of both the non-migrants in the sending countries due to ageing, and migrants with little formal education taking jobs in precarious working conditions and having to take care of their new families in the immigrant countries. Additionally, the specific migration context in Emirdağ-in which massive emigration has completely changed the demographic composition of the community-has meant that it has not been able to compensate for the loss of a generation of children, who were assumed would take care and provide for the elderly within this society and traditional care system. The combination of these factors has led to a change in the culture of migration and left the zero generation disappointed. The distorted circulation of care has impacted the migration dynamics and the prevailing culture of migration in Emirdağ unequivocally and unintentionally, and lays bare the lack of structural care provision for elderly in this region.

Finally, this study has shown that there is a gap between the demand for care and care provision in Emirdağ. While the interviewees related their lack of care and the direct consequences of this, such as loneliness and health problems, to the downsides of their children's migration (physical absence of relatives, financial difficulties), previous studies on elderly care in Turkey highlight other factors that are also at play here. For example, it has been argued that feelings of loneliness among elderly people in Turkey are more prevalent than in other countries due to a general transition in family structure to nuclear families and inadequate services (Aylaz, Aktürk, Erci, Öztürk, \& Aslan, 2012, p. 551). It is important that national and international policies aimed at improving elderly people's standards of living in Turkey take into account this full array of socio-political conditions, including the less obvious factor of migration, as we argue here. An interesting comparison can also be drawn with research on elderly care in other Mediterranean countries. In Spain and Italy, for example, a similarly high demand for elderly care, attributed to population ageing and the entrance of women into the formal labour market, has had a different effect on migration patterns: it has stimulated the immigration of foreign, mostly female, carers to work in the domestic sector as a replacement for family care (Bettio, Simonazzi, \& Villa, 2006; León, 2010).

As a recommendation for both future research and policy consideration, we would like to propose here that an international comparison might prove insightful in relation to the question of why similar responses to the demand for elderly care are not yet emerging in Turkey, and on the intricate relationship between elderly care and migration. Additionally, as a contribution to theory on transnational care and the zero generation, greater attention should be paid to the way in which financial care and direct, instrumental care are interlinked, as these forms of care are usually treated separately. It would also be of value to understand how this relationship af- fects or even disrupts the prevailing care arrangements for the elderly and family ties (Zimmer, Codrina, \& Stoica, 2014; Zimmer \& Knodel, 2013). We found that for the very elderly zero generation of Emirdağ and their migrant offspring, the latter cannot make up for their failure to provide financially, as due to changing demographics, there are few possibilities available to provide instrumental care.

\section{Acknowledgments}

This project was funded by the Koning Boudewijnstichting.

\section{Conflict of Interests}

The authors declare no conflict of interests.

\section{References}

Antman, F. (2013). The impact of migration on family left behind. In F. Constant \& K. F. Zimmermann (Eds.), An international handbook on the economics of migration (pp. 293-308). Cheltenham-Northampton: Edward Elgar Publishing Limited.

Aylaz, R., Aktürk, Ü., Erci, B., Öztürk, H., \& Aslan, H. (2012). Relationship between depression and loneliness in elderly and examination of influential factors. Archives of Gerontology and Geriatrics, 55(3), 548-554.

Baldassar, L., \& Merla, L. (2014). Transnational families, migration and the circulation of care: Understanding mobility and absence in family life. New York, NY: Routledge.

Basara, B. B., Mollahaliloglu, S., Pulgat, E., \& Kavuncubasi, S. (2014). Gender and residency effects on elderly health in Turkey. Ageing International, 39(1), 55-67.

Bettin, G., Elitok, P. S., \& Straubhaar, T. (2012). Causes and consequences of the downturn in financial remittances to Turkey: A descriptive approach. In S. P. Elitok \& T. Straubhaar (Eds.), Turkey, migration and the EU: Potentials, challenges and opportunities (pp. 133-166). Hamburg: Hamburg University Press.

Bettio, F., Simonazzi, A., \& Villa, P. (2006). Change in care regimes and female migration: The 'care drain' in the Mediterranean. Journal of European Social Policy, 16(3), 271-285.

Bilecen, B. (2013). Transnational family networks of migrants from Turkey in Europe. Turkish Journal of Sociology, 3(27), 219-234.

Böhme, M. H., Persian, R., \& Stöhr, T. (2015). Alone but better off? Adult child migration and health of elderly parents in Moldova. Journal of Health Economics, 39(2015), 211-227. https://doi.org/ 10.1016/j.jhealeco.2014.09.001

Coles, R. L. (2001). Elderly narrative reflections on the contradictions in Turkish village family life after migration of adult children. Journal of Aging Stud- 
ies, 15(4), 383-406. https://doi.org/10.1016/S08904065(01)00030-5

De Haas, H. (2001). The determinants of international migration: Conceiving and measuring origin, destination and policy effects (DEMIG/IMI Working Paper 32). Oxford: International Migration Institute, University of Oxford.

De Haas, H. (2007). Remittances, migration and social development: A conceptual review of the literature (Social Policy \& Development Programme Paper 34) Geneva: United Nations Research Institute for Development.

De Haas, H., Fokkema, T., \& Fihri, M. F. (2015). Return migration as failure or success? The determinants of return migration intentions among Moroccan migrants in Europe. Journal of International Migration and Integration, 16(2), 415-429.

Içduygu, A. (2005). International migrants remittances in Turkey. Fiesole: European University Institute.

Içduygu, A., \& Sert, D. (2016). A debate over return migration: The case of Turkish guest workers in Germany. In D. L. Lealand \& N. P. Rodríguez (Eds.), Migration in an era of restriction and recession: Sending and receiving nations in a changing global environment (pp. 259-272). Switzerland: Springer International Publishing.

Karcı, K. D., Üstübici, A., \& De Clerck, H. (2010). Turkey country and research areas report (Project Paper 5). Oxford: Eumagine, Imagining Europe from the Outside.

King, R., Cela, E., Fokkema, T., \& Vullnetari, J. (2014). The migration and well-being of the zero generation: Transgenerational care, grandparenting, and loneliness amongst Albanian older people. Population, Space and Place, 20(8), 728-738. https://doi.org/ 10.1002/psp.1895

Koc, I., \& Onan, I. (2006). International migrants' remittances and welfare status of the left-behind families in Turkey. International Migration Review, 38(1), 78-112. https://doi.org/10.1111/j.1747-7379. 2004.tb00189.x

Kuhn, R., Everett, B., \& Silvey, R. (2011). The effects of children's migration on elderly kin's health: A counterfactual approach. Demography, 48(1), 183-209. https://doi.org/10.1007/s13524-010-0002-3

León, M. (2010). Migration and care work in Spain: The domestic sector revisited. Social Policy and Society, 9(3), 409-418.

Nedelcu, M. (2009). La generation zero: du sedentaire a l'acteur circulant. Effets de mobilité sur la generation des parents des migrants Roumains hautement qualifiés à Toronto à l'ère du numérique. In G. Cortes \& L. Faret (Eds.), Les circulations transnationales: Lire les turbulences migratoires contemporaines (pp. 187198). Paris: Armand Colin.

Şenyürekli, A. R., \& Detzner, D. F. (2008). Intergenerational relationships in a transnational context: The case of Turkish families. Family Relations, 57(4), 457-467. https://doi.org/10.1111/j.17413729.2008.00514.x

Şenyürekli, A. R., \& Menjivar, C. (2012). Turkish immigrants' hopes and fears around return migration. International Migration, 50(1), 3-19.

Teule, J., Vanderwaeren, E., Mbah-Fongkimeh, A., \& Timmerman, C. (2012). La migration par le mariage d'Emirdağ. Bruxelles: Fondation Roi Baudouin.

Timmerman, C. (1995). Cultural practices and ethnicity: Diversifications among Turkish young women. International Journal of Educational Research, 23(1), 23-32.

Timmerman, C. (2006). Gender dynamics in the context of Turkish marriage migration: The case of Belgium. Journal of Turkish Studies, 7(1), 125-143.

Timmerman, C. (2008). Marriage in a "culture of migration": Emirdag marrying into Flanders. European Review: Interdisciplinary Journal of the Academia Europaea/Academia Europaea, 16(4), 585-594.

Timmerman, C., Hemmerechts, K., \& De Clerck, H. (2014). The relevance of a "culture of migration" in understanding migration aspirations in contemporary Turkey. Turkish Studies, 15, 496-518. https:// doi.org/10.1080/14683849.2014.954748

Timmerman, C., Lodewyckx, I., \& Wets, J. (2009). Marriage at the intersection between tradition and globalization: Turkish marriage migration between Emirdag and Belgium from 1989 to present. The History of the Family, 14(2), 232-244.

TurkStat. (2015). Latest press releases. Turkstat.Gov. Retrieved from www.turkstat.gov.tr/Start.do

Van Kerckem, K., Van de Putte, B., \& Stevens, P. (2013). On becoming "too Belgian": A comparative study of ethnic conformity pressure through the city-as-context approach. City \& Community, 12(4), 335-360, https://doi.org/10.1111/cico.12041

World Bank. (2015). Personal remittances. WorldBank. Retrieved from data.worldbank.org/indicator/BX. TRF.PWKR.CD.DT

Zimmer, Z., \& Knodel, J. (2013). Older-age parents in rural Cambodia and migration of adult children. Asian Population Studies, 9(2), 156-174. https://doi.org/ 10.1080/17441730.2013.797297

Zimmer, Z., Codrina, R., \& Stoica, C. A. (2014). Migration, location and provision of support to older parents: The case of Romania. Population Ageing, 7, 161-184. https://doi.org/10.1007/s12062-014-9101-z 


\section{About the Authors}

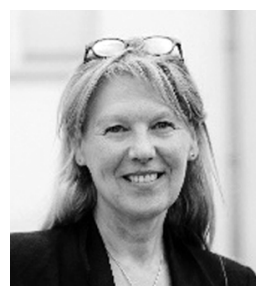

Christiane Timmerman (MA Psychology; MA, PhD Social and Cultural Anthropology, KULeuven) is a Full Professor (Research Professor-ZAPBOF) at the University of Antwerp and Director of the Centre of Migration and Intercultural Studies (CeMIS). Her focus is on multidisciplinary research on migration, integration and ethnic minorities. She has built extensive experience coordinating large scale research projects on international migration and integration.

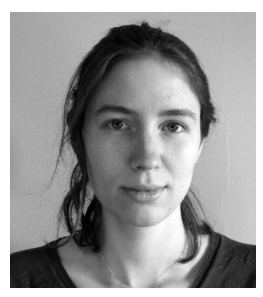

Meia Walravens (MA Arabic and Islamic Studies, KU Leuven; MA South Asian Area Studies, SOAS, University of London) is a PhD student in the Department of History at the University of Antwerp, Belgium. She previously worked as a Researcher at the Centre for Migration and Intercultural Studies (CeMIS) at the University of Antwerp and at the Max Planck Institute for Social Anthropology in Halle/Saale, Germany. Her research interests include Islamic history and Arabic, Persian and Turkish studies.

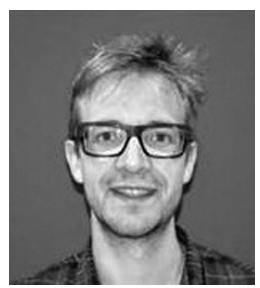

Joris Michielsen (Master en Evaluation et Gestion du Développement, University of Antwerp) holds an $\mathrm{MA}$ and $\mathrm{PhD}$ in Sociology. His interests are on medical sociology, theory-driven evaluation, Bourdieu, access to health care, social protection in health, urban health, empowerment and emancipation processes, social change, mutuals, poverty and exclusion impact evaluation and systematic reviews.

Nevriye Acar (MA Psychology, Free University of Brussels), is a Clinical Psychologist who is mainly specialised in fieldwork and data collection.

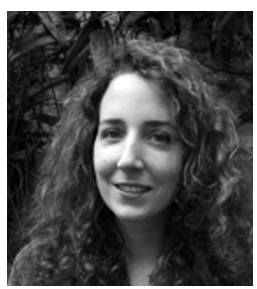

Lore Van Praag (MA, PhD Ghent University) is working as a Post-Doctoral Researcher at the University of Antwerp. Her research interests are interethnic relations in schools, tracking, discrimination, early school leaving, ethnography, climate change and migration aspirations. 